\title{
Television and anti-immigrant sentiments. The mediating role of fear of crime and perceived ethnic diversity.
}

Laura Jacobs, Marc Hooghe \& Thomas de Vroome

Accepted for publication in European Societies: 10.1080/14616696.2017.1290264.

\begin{abstract}
Previous research has established a correlation between fear of crime and antiimmigrant sentiments. In this paper, we explore the role of television in explaining individual differences in fear of crime, perceived ethnic diversity and anti-immigrant sentiments. We use the 'Social Cohesion Indicators in Flanders' data, a representative survey in the Flemish region of Belgium, combined with real life indicators of ethnic diversity and crime at the community level. Results of a multilevel structural equation model suggest that watching television is positively associated with fear of crime and perceived ethnic diversity, which in turn is associated with anti-immigrant sentiments. Preference for public television is, however, associated with lower anti-immigrant sentiments, perceived ethnic diversity and fear of crime levels. Real crime and ethnic diversity levels are only weakly related to anti-immigrant sentiments. We conclude that especially perceptions are important in influencing antiimmigrant sentiments and that television use is associated with these perceptions.
\end{abstract}

Key words: Television, Anti-immigrant Sentiments, Fear of Crime, Crime, Perceived Ethnic Diversity 


\section{Introduction}

As the ethnic composition of Western societies is becoming increasingly diverse, the immigration issue has moved toward the center of political debate (Kriesi et al. 2012). The antiimmigrant rhetoric of radical right-wing parties associates immigrants with social disorder and crime (Rydgren 2008). The mass media could also contribute to perceived associations between ethnic diversity, fear of crime and anti-immigrant sentiments, as immigration is increasingly framed from a criminal threat perspective (Fryberg et al., 2012; Lawlor, 2015) Moreover, the high prominence of immigration issues in news is associated with increased public scrutiny of immigration figures and policies, as well as with an overestimation of immigration statistics (Dunaway, Branton, Abrajano, \& Diego, 2010). There is not much research, however, on the mechanisms through which television can impact anti-immigrant sentiments. In this study, relying on threat theory, we investigate the association between television consumption and anti-immigrant sentiments, and the extent to which perceived ethnic diversity and fear of crime mediate this relation.

We complement previous research by offering several important additions. First, we evaluate both direct and indirect effects of television viewing on anti-immigrant sentiments. Second, we take into account potential confounding factors (e.g. audience traits, neighborhood characteristics, the type of television exposure). As such, we can ascertain whether the correlation between television viewing and attitudes is robust, and holds while controlling for real-life data on crime and ethnic diversity. This allows us to determine what matters most in explaining anti-immigrant sentiments: objective conditions, or perceptions of threat and diversity? We extend recent work suggesting that especially perceptions are important in this regard (Hooghe \& de Vroome, 2015; Raijman \& Semyonov, 2004) by determining how television consumption might affect these perceptions. Third, we explicitly bring in fear of crime as an important element underlying anti-immigrant sentiments. This factor has been 
understudied in Western European contexts as most research investigating anti-immigrant sentiment focused on economic and cultural threat (Citrin, Green, Muste, \& Wong, 1997; Hainmueller \& Hiscox, 2010), neglecting the role of fear of crime and (perceived) overrepresentation of immigrants in criminal acts (Dinas \& van Spanje, 2011; Fitzgerald, Curtis, \& Corliss, 2011).

\section{Threat theory and anti-immigrant sentiments}

The available research in intergroup relations has offered compelling evidence that antiimmigrant sentiments are largely driven by feelings of threat. Intergroup threat, as reviewed by Riek, Mania and Gaertner (2006, p. 336), can be defined as the threat experienced 'when one group's actions, beliefs or characteristics challenge the goal attainment or well-being of another group'. Threats can take many shapes. Generally, when assessing anti-immigrant sentiments, research in Western Europe has primarily focused on economic and cultural sources of threat (Citrin et al., 1997; Hainmueller \& Hiscox, 2010; Raijman \& Semyonov, 2004; Schneider, 2008). However, other sources have been identified too. Some studies have emphasized contextual factors, such as immigrant presence in society (Schlueter \& Scheepers, 2010; Schneider, 2008), whereas recently also perceived criminal threat posed by immigrants has attracted - albeit rather limited - scholarly attention (Ceobanu, 2011; Fitzgerald et al., 2011; Stupi, Chiricos, \& Gertz, 2014).

First, the presence of immigrants or outgroup size in a given society has been suggested to affect feelings of threat (Kunovich, 2004; Quillian, 1995; Schlueter \& Scheepers, 2010; Semyonov, Raijman, \& Gorodzeisky, 2006). This can be explained within ethnic competition theory, which stresses that the demographic composition of society-the relationship between ingroup and outgroup-may increase intergroup competition. A larger outgroup, such as rising numbers of immigrants, might induce conflict over material resources and cultural tensions 
about norms and values (Ivarsflaten, 2005). This assumption, however, is not always supported by empirical evidence (Sides \& Citrin, 2007; Strabac \& Listhaug, 2008). Previous studies have revealed a weak relation between real immigrant presence and anti-immigrant sentiments: especially the perception of outgroup size plays a key role (Hooghe \& de Vroome, 2015; Semyonov et al., 2006). Moreover, research has routinely found that large discrepancies exist between real and perceived immigrant presence (Alba, Rumbaut, \& Marotz, 2005). These inaccurate perceptions of immigrant presence levels are expected to foster anti-immigrant sentiments as these might activate feelings of threat (Schlueter \& Davidov, 2013; Semyonov et al., 2006).

Second, recent research suggests that an association is being made between the issues of crime and safety and immigration in the minds of the public (Bircan \& Hooghe, 2011; Ceobanu, 2011; Dinas \& van Spanje, 2011; Fitzgerald et al., 2011). A 2011 comparative study found that a majority of native citizens in Western Europe agreed that crime problems in society are rendered worse by immigration (Fitzgerald et al., 2011). Moreover, comparison of these perceived criminal threats with cultural and economic arguments revealed that the claim that immigrants contribute to crime received significantly more support among citizens than other forms of threat. Despite this widespread belief that immigration is positively associated with crime, compelling empirical evidence linking immigrants with (an increase in) crime levels is lacking (Stupi et al., 2014).

\section{The Role of Television}

Intergroup threats are considered important determinants of negative attitudes toward immigrants. Compelling evidence for the role of real immigrant presence, and for a real association between crime and immigration is, however, scarce. This leaves us with an intriguing research puzzle: if the presence of immigrants does not increase crime, why do 
citizens think this association does occur? And why do citizens consistently overestimate diversity levels, which may lead to distorted perceptions and trigger threat? Which factors cause the public to hold these beliefs? Past research has stressed that threats do not need to be real, but that perceptions are a sufficient condition (LeVine \& Campbell, 1972). How are these perceptions shaped? To disentangle this discrepancy between reality and public perceptions, we highlight the role of media, and television news in particular, as important determinant of anti-immigrant sentiments by affecting threat perceptions. A large body of research indeed assesses the role of the news media in the formation of anti-immigrant sentiments (Boomgaarden \& Vliegenthart, 2009; Schemer, 2012; Schlueter \& Davidov, 2013; Van Klingeren, Boomgaarden, Vliegenthart, \& De Vreese, 2014).

First, with regard to perceived ethnic diversity, immigration and integration have become increasingly salient issues in Western mass media (Bauder, 2008). Moreover, these stories often tend to be sensational in nature (Charteris-Black, 2006). Media theories on agenda setting assume that public opinion evaluates issues as more pressing if they are perceived to attract media attention (Iyengar \& Kinder, 1987). Hence, if television extensively reports on immigration-related issues, this can be expected to affect perceptions of immigrant presence among the majority population (Schlueter \& Davidov, 2013). A recent study on immigration coverage has found evidence that a portion of the effect of immigration on attitudes is related to media reporting about immigration (Van Klingeren et al., 2014). This study concluded that real-world immigration numbers have little bearing on the salience of immigration, whereas news content was highly effective in shaping attitudes toward immigrants.

Second, with regard to fear of crime, crime coverage on the news is often considered an important contributing factor. Crime presents an important ingredient of television news, as conflict is judged attractive, straightforward, and therefore accessible and well-suited to reach large audiences (Lowry, Nio, \& Leitner, 2003). More importantly, a particular element of media 
framing of crime is the frequent association between immigration and crime. Content analysis of media messages has shown that immigration is increasingly depicted as a security threat and that immigrants are increasingly associated with crime, terrorism and law and order issues (Caviedes, 2015; Dinas \& van Spanje, 2011; Lawlor, 2015). Some studies have noted that crime and deviant behavior are dominant themes in news stories on immigrants (Lubbers, Scheepers, \& Wester, 1998). This well-documented criminal framing of immigrants in news media, may foster perceptions that immigrants are overrepresented in crime statistics, and thus impact fear of crime levels and anti-immigrant sentiments (Dinas \& van Spanje, 2011).

In sum, to the extent that immigration is a visible issue on television, and is framed from a criminal perspective, it can be expected that perceived ethnic diversity and fear of crime may mediate the role between television consumption and anti-immigrant sentiments..

\section{Audience Traits, Neighborhood Characteristics and Television Type}

In the early years of cultivation theory it was assumed that heavy television viewers would believe that the world as depicted on television closely resembles the real world (Gerbner, Gross, Morgan, Signorielli, \& Shanahan, 2002). This vision, however, has been criticized for neglecting potential confounding factors, such as the diverse nature of the audience, real-life indicators, and the complexity of the television market (Chadee \& Ditton, 2005).

First, the strength of television effects on attitudes is conditional on the type of audience (Iyengar \& Kinder, 1987). Television viewing should be approached as a dynamic process where the audience actively interprets the meaning of television messages (Gray \& Lotz, 2011). This suggests that television effects might diverge according to personal background and experience. Replication studies assessing the relationship between television consumption and fear of crime, for instance, have found that audience traits (e.g. age, gender, socioeconomic 
status, victimization experiences) greatly matter (Eschholz, Chiricos, \& Gertz, 2003; Heath \& Gilbert, 1996).

Second, the 'real-world thesis' suggests that the relationship between television and attitudes is mediated by objective conditions, such as neighborhood characteristics (Weitzer \& Kubrin, 2004). The underlying rationale is that television's influence will be weaker if messages are perceived to bear little relevance for individuals' immediate environment. Relevant neighborhood characteristics for our study are crime rates and the neighborhood's ethnic composition (Eschholz et al., 2003; Quillian \& Pager, 2001; Weitzer \& Kubrin, 2004).

Third, authors have stressed the need to adopt a multidimensional perspective when investigating television effects, differentiating between specific television content, type and programs (Esser \& de Vreese, 2007; Hooghe, 2002). Especially in Western Europe, we may expect differences between commercial and public broadcasting (Schmitt-Beck \& Wolsing, 2010). Public broadcasters are generally expected to serve the public good (Holtz-Bacha \& Norris, 2001), and they have sometimes explicitly engaged themselves to promote tolerance and diversity. Commercial stations, on the other hand, are mainly guided by profit and audience maximization, making these stations more inclined to broadcast sensational reports about crime and immigration (Holtz-Bacha \& Norris, 2001; Schmitt-Beck \& Wolsing, 2010). A study investigating the media salience of crime issues in the Belgian context, has found that the main commercial broadcaster in Belgium devotes twice as much attention to crime stories as the public broadcasting corporation (Walgrave \& De Swert, 2002). Furthermore, a recent EU study concluded that public broadcasters more carefully represent cultural diversity in their program content (Rogers, O’Boyle, Preston, \& Fehr, 2014). When investigating the relation between media consumption and fear of crime, it is important, therefore, to pay attention to these factors.

\section{Hypotheses}


The theory and literature review lead to the following hypotheses:

H1: Watching television is positively associated with perceived ethnic diversity, fear of crime, and anti-immigrant sentiments.

H2: A preference for public television is associated with lower anti-immigrant sentiments, perceived ethnic diversity and fear of crime.

H3: The relation between television consumption and anti-immigrant sentiments is partially mediated by fear of crime and perceived ethnic diversity.

H4: Television consumption patterns are associated with anti-immigrant sentiments, perceived ethnic diversity and fear of crime, even when controlling for audience traits and neighborhood characteristics.

\section{Data, Method and Measurements}

\subsection{Data}

We rely on data from the Social Cohesion Indicators in Flanders (SCIF) survey. The SCIF survey was carried out in 2009 among a representative sample of the adult population in Flanders, i.e. the Dutch-speaking northern region of Belgium. This survey was specifically designed to provide an adequate overview of patterns of social cohesion in Flanders. In faceto-face interviews, 2,085 citizens were questioned on their media use, attitudes and sociodemographic characteristics. The contact procedure was as follows: all the selected addresses received an informative official letter in advance of the interviewer's first visit explaining the scope and aims of the project. The letter emphasized the confidentiality of the study. Within two weeks after the letters were sent, respondents were contacted face-to-face. Respondents that were unreachable at the first visit were revisited minimum four times. The response rate was $54 \%$, which is an average rate for surveys in Belgium. Like other European countries, Belgium is confronted with a phenomenon of declining response rates in population surveys, 
so the $54 \%$ conforms to accepted scientific standards (Hooghe, Vanhoutte, \& Bircan, 2009). Five percent of respondent candidates were eliminated due to language barrier as their level of Dutch, the language of the questionnaire, was insufficient. Again, we would like to stress that this type of response pattern is typical for countries like Belgium, the Netherlands or Germany. Only respondents that were born in Belgium and of whom both parents were born in Belgium were included, so that we assess anti-immigrant sentiments among the native majority population. The respondents are nested in 40 randomly selected municipalities, resulting in a hierarchical data structure. The individual-level data are supplemented with real-life indicators at the municipal level. More specifically, municipalities' crime and ethnic diversity levels are taken up as neighborhood characteristics. The data on the ethnic diversity of the municipality are derived from the Belgian National Institute of Statistics. The data on municipalities' crime levels were obtained from the Belgian Federal Police, encompassing the registration of criminal activities by federal and local police forces. Crime statistics always underestimate real crime occurrence, but the Belgian federal police has invested extensively in establishing a reliable database on the registration of criminal acts, increasing the validity of the data. Municipalities in Flanders are rather small with on average 20,000 inhabitants, so that they can still be considered to constitute a neighborhood environment.

\subsection{Measurements}

\subsubsection{Dependent Variable.}

The dependent variable, anti-immigrant sentiments, is measured as an eleven-point scale composed of respondents' assessments of three items on immigration which have been validated by previous studies. These items are regularly used in cross-national studies, e.g. the European Social Survey (ESS), as indicators of 'anti-immigrant sentiments' (Rustenbach, 2010). Respondents had to judge the consequences of immigration for the country in general, 
the economy and its cultural life. The exact wording was: "Would you say it is generally good or bad for Belgium's economy that people come to live here from other countries?", "Would you say that Belgium's cultural life is generally enriched or undermined by people coming to live here from other countries?" and "Is Belgium made a better or a worse place to live by people coming to live here from other countries?'. The answers were coded on an eleven-point scale ranging from 0 (indicating a very positive assessment) to 10 (indicating a very negative assessment $)(\mathrm{M}=4.92, \mathrm{SD}=1.83)$. Higher values correspond with more negative attitudes toward immigrants. The unidimensionality of these items is shown by a principal component analysis (Cronbach's $\alpha$ : .73, Eigenvalue: 1.95, explained variance: 64.85).

\subsubsection{Mediators}

Perceived percentage of non-Belgians. This variable refers to the perceived level of ethnic diversity and was operationalized by asking respondents to estimate the percentage of non-Belgians currently living in Belgium. This variable ranges from one percent to ninety-nine percent $(\mathrm{M}=27.18, \mathrm{SD}=16.74)$.

Fear of crime. To operationalize fear of crime, we have adapted the avoidance behavior scale from the Belgian Security Monitor, which measures the behavioral component of fear of crime (Hooghe et al., 2009). This variable was measured with an assessment on five-point scales, ranging from 'never' to 'very often', of the following three items: 'I avoid certain areas in my neighborhood because I think they are not safe', 'I avoid to open the door to strangers because I think it is not safe', 'I avoid leaving home after dark because I think it is not safe'. The scale is unidimensional (Cronbach's $\alpha:$.71, Eigenvalue: 2.295, explained variance: 57.39 ), ranging from zero to four $(\mathrm{M}=0.58, \mathrm{SD}=0.72)$.

\subsubsection{Independent Variables}


Television Variables. The first variable refers to the amount of time spent watching television and was measured by asking respondents the following question: 'How many hours do you spend watching television on an average weekday?' The answers range from no time at all to 11.5 hours $(\mathrm{M}=2.40, \mathrm{SD}=1.56)$. Respondents were also asked to indicate their preferred television station. Respondents chose from a detailed list that included the most frequently watched public and commercial television stations in Flanders. The answers were used to construct a dummy variable indicating whether respondents prefer a commercial or public television station $(\mathrm{M}=0.54)$. Although this variable does not specifically assess television exposure, a preference measure is considered more optimal as it reduces possible bias in selfreporting (Prior, 2009). Moreover, statistics show that the answers reflect actual market shares (European Audiovisual Observatory, 2014). US Studies have suggested that especially local television is important when studying fear of crime (Chiricos et al., 2000; Weitzer \& Kubrin, 2004). In Flanders, however, market shares of local television are limited (European Audiovisual Observatory, 2014). Flanders has approximately 6 million inhabitants and covers a geographical area of 5,221 square miles. We therefore assume that information brought to the audience by regional Flemish broadcasters can be considered sufficiently realistic and proximate for most viewers.

Audience Traits and Neighborhood Characteristics. ${ }^{1}$ Both audience traits and neighborhood characteristics are taken up to avoid spurious effects, as they can offer alternative explanations when assessing anti-immigrant sentiments (Aarts \& Semetko, 2003). The audience traits at the individual level concern mostly socio-demographic background variables. Gender is included since women tend to be more fearful of crime, but more tolerant towards immigrants (Valentova \& Alieva, 2014). Men were coded as 0, and women were coded as 1

\footnotetext{
${ }^{1}$ We do not include racial or ethnic prejudice as control variable in the analysis, as analyses showed that in Western Europe this measure very strongly correlates with anti-immigrant sentiments.
} 
$(M=0.51)$. Age in years is taken up $(M=48.42, S D=17.85)$, as older respondents tend to be more fearful and more negative toward immigrants (Chiricos et al., 2000; O'Rourke \& Sinnott, 2006). Moreover, especially economically disadvantaged segments of society would be more susceptible to anti-immigrant sentiments (Burns \& Gimpel, 2000; Eschholz et al., 2003). The realistic group conflict theory implies that citizens who are vulnerable to economic fluctuations and consequently undergo changes in their individual economic position (e.g. lower wage, becoming, being or having been unemployed) may feel more threatened by immigrants (Citrin et al., 1997; Kunovich, 2013; Lancee \& Pardos-Prado, 2013; Quillian, 1995). Moreover, vulnerability theory suggests that low status individuals typically may feel more unsafe as they are vulnerable social groups (Visser, Scholte, \& Scheepers, 2013). Three variables are included to operationalize respondents' objective and subjective socio-economic status and economic vulnerability: educational level, employment status and income satisfaction. First, respondents were asked about the highest level of education they have completed. This variable has five categories, ranging from 'no education' to 'tertiary education' $(\mathrm{M}=3.08, \mathrm{SD}=1.13)$. Second, respondents were asked whether they have ever been unemployed for a period of more than six months as this allows us to identify individuals in precarious economic situations. ${ }^{2}$ This variable is included as a dummy variable $(\mathrm{M}=0.15)$. Third, we take up a subjective measurement and include respondents' level of satisfaction with the household income. This variable is measured on a six-point scale ranging from zero ('very difficult to live on present household income') to five ('very easy to live on present household income') ( $\mathrm{M}=3.45, \mathrm{SD}=1.08)$. Income satisfaction is preferred over actual income data, because of the high proportion of missing answers $(15 \%)$ on this latter question. Other individual-level audience traits that are controlled for are victimization, religiosity, life satisfaction, household structure, intergroup friendship and

\footnotetext{
${ }^{2}$ There is no specific theoretical reason to assume that the effect of unemployment experiences would disappear after a specific number of years, but we simply had to include the question as it was phrased in this survey.
} 
left-right self-placement. Victimization is a dichotomous variable referring to "whether the respondent has been victim of a criminal act in the last five years' $(M=0.16){ }^{3}$ In line with previous research we expect victimization to be positively related to fear of crime (Chiricos, Hogan, \& Gertz, 1997; Pickett, Chiricos, Golden, \& Gertz, 2012; Quillian \& Pager, 2001; Weitzer \& Kubrin, 2004). Respondents' religiosity is measured by asking respondents whether they identify with a denomination or religion or not $(\mathrm{M}=0.49)$. Research suggests that religion can be related to attitudes on immigrants and fear of crime, although it is inconclusive on the direction (Bohman \& Hjerm, 2013). Self-reported life satisfaction is measured on a scale ranging from zero ('extremely dissatisfied') to ten ('extremely satisfied') ( $\mathrm{M}=7.95, \mathrm{SD}=1.53$ ). Life satisfaction is expected to lower negative feelings such as fear of crime and anti-immigrant sentiments (Hooghe, 2012). Respondents' household structure is taken up as dichotomous variable referring to a single household or not $(\mathrm{M}=0.12)$, since previous research has established that persons living in single households are more vulnerable for feelings of social isolation, and hence also for threat (Ross, Mirowsky \& Pribesh, 2001). Intergroup friendship is included as contact theory suggests intergroup contact reduces anti-immigrant sentiments (Pettigrew \& Tropp, 2008). Maintaining meaningful contacts (such as friendship) with members of minority or immigrant groups forms a powerful buffer against prejudice. Respondents were asked about they have friends with other ethnic backgrounds or not $(\mathrm{M}=0.35)$. Finally, respondents' political left-right orientation was assessed by asking them to place themselves on a left-right scale ranging from zero to ten $(\mathrm{M}=5.37, \mathrm{SD}=2.09)$. Ample evidence shows that a right-wing ideology is positively correlated to negative attitudes toward immigration, as (extreme) right-wing parties tend to take a rigid and strict stance on immigration, favoring immigration restrictions (Rydgren, 2008).

\footnotetext{
${ }^{3}$ Victimization thus asks about any punishable act. A measure asking about specific types of crime (e.g. assault, robbery) could have presented a better measure, but was not available.
} 
At the municipality level, ethnic diversity and crime levels are taken up. ${ }^{4}$ In Belgium, ethnic diversity mainly refers to the presence of migrant populations from Turkey and Morocco that have arrived as guest workers and via family reunification in the $1960 \mathrm{~s}$, as these are the largest immigrant groups in Belgium (Morelli, 2004). Measurements of anti-immigrants sentiments show that these sentiments do not have a bearing on immigrants from neighboring European countries, but specifically refer to immigrants and their descendants from outside Western Europe (Hooghe \& de Vroome, 2015; Semyonov et al., 2006). The level of ethnic diversity is operationalized as the percentage of Turks $(\mathrm{M}=0.37, \mathrm{SD}=0.58)$, Moroccans $(\mathrm{M}=0.36, \mathrm{SD}=0.67)$ and Eastern Europeans $(\mathrm{M}=0.91, \mathrm{SD}=0.80)$ present in the municipality. This data comes from the official statistical office in Belgium. It has to be noted here that Belgian population data do not include any information at all about ethnic descent of inhabitants with Belgian nationality. Therefore, the only information we have available is based on citizenship status. In practice this means that the ethnic diversity is underestimated, as we do not have information about, e.g., inhabitants of Turkish descent, but having Belgian nationality. A previous analysis, however, has shown that the correction between this official measurement (based on nationality), and a more comprehensive measurement based on various cultural markers of ethnic descent is .99 at the community level. This implies that those with Turkish nationality indeed live in exactly the same neighborhoods as inhabitants from Turkish descent but with the Belgian nationality. The very strong correlation of .99 would imply that in practice

\footnotetext{
${ }^{4}$ Prior research suggested that especially changes in levels of ethnic diversity are important (Hawley, 2011; Hopkins, 2010; Meuleman, Davidov \& Billiet, 2009; Stupi, Chiricos \& Gertz, 2014). We have therefore also used the change over the last nine years before the survey as community-level independent variable. This measure, however, is not ideal as many Flemish communities are rather small, so that results are based on small numbers and are not always reliable. Most likely as a consequence, results of this analysis proved to be rather unstable.
} 
this variable does not make a difference, but for reasons of reliability we stick to the official data.

Also the inflow of foreigners as a percentage of the municipality's population size is included $(\mathrm{M}=0.39, \mathrm{SD}=0.32)$. For municipalities' crime levels, violent and property crime rates are included. These figures are weighted by the municipality size, thus referring to the amount of violent and property criminal acts per 1,000 inhabitants.

\subsection{Method}

The theoretical model predicts the existence of both direct and indirect relations between patterns in television use and anti-immigrants sentiments. In order to test this theoretical model, we conducted structural equation modeling (SEM) (Kline, 2011). Since the data structure is hierarchical, containing information on individuals (level 1) nested in municipalities (level 2), multilevel SEM was conducted.

\section{Results}

Table 1 first displays the audience traits and neighborhood characteristics to evaluate hypothesis 4 . Women have lower anti-immigrant sentiments $(b=-.244, p<.01)$, while older respondents have more negative attitudes toward immigrants $(b=.010, p<.001)$. Respondents' socioeconomic status is important, as especially the lower-educated $(b=-.265, p<.001)$, and respondents dissatisfied with their household income $(b=-.0 .66, p<.05)$ evaluate immigrants more negatively. Respondents that are satisfied with their lives $(b=-.123, p<.001)$, religious $(b=-.76, p<.01)$ and report intergroup friendship $(b=-.678, p<.001)$ also hold less anti-immigrant sentiments. Political ideology matters, as right-wing respondents $(b=.122, p<.001)$ evaluate immigrants more negatively. Second, we observe that generally women $(b=.347, p<.001)$ and older respondents $(b=.004, p<.01)$ are more fearful. Higher-educated respondents $(b=-.051$, 
$\mathrm{p}<.001$ ), however, display lower fear of crime levels. Intergroup friendship is also negatively correlated with fear of crime $(b=-.083, p<.05)$. Finally, religious respondents $(b=.119, p<.001)$ and respondents recently victimized $(b=.136, \mathrm{p}<.01)$ report higher fear of crime levels. Third, considering perceived ethnic diversity levels, especially women $(b=8.464, p<.001)$, young $(b=-$ $.127, \mathrm{p}<.001)$, right-wing $(\mathrm{b}=.488, \mathrm{p}<.01)$, single-household $(\mathrm{b}=2.672, \mathrm{p}<.05)$, and long-term unemployed respondents $(b=1.735, \mathrm{p}<.10)$ perceive higher ethnic diversity levels. The highly educated $(b=-2.211, p<.001)$ report lower levels of perceived ethnic diversity. Next, we consider the neighborhood characteristics. For anti-immigrant sentiments, neighborhood characteristics are only marginally important. Only the percentage of Moroccans living in the neighborhood is positively correlated to anti-immigrant sentiments $(b=.291, p<.01)$. Also real crime levels are not significantly related to anti-immigrant sentiments. For fear of crime, we note - interestingly - that municipalities' real crime and ethnic diversity levels are not related to fear of crime. Finally, considering perceived ethnic diversity, only the presence of Turks $(b=2.802, p<.05)$ and Moroccans $(b=3.336, p<.001)$ in neighborhoods is positively related to perceived ethnic diversity.

-Table 1-

Table 2 and Figure 1 present a formal test of the total, direct and indirect relationships between television consumption and anti-immigrant sentiments. The results in Table 2 confirm that the indirect relations via fear of crime and the perceived percentage of non-Belgians are statistically significant, confirming hypothesis 1 to 3 .

-Table 2-

Figure 1 visually displays the direct and indirect relations between television consumption and anti-immigrant sentiments, controlling for audience traits and neighborhood 
characteristics $^{5}$. It should be noted here that, when conducting multilevel SEM, standardized coefficients are not meaningful as relations refer to different levels of analysis (individual and contextual). We therefore cannot compare the relations in size, and focus on interpreting the significance of the relations. There is no direct relationship between the amount of time spent watching television and anti-immigrant sentiments, but fear of crime and perceived ethnic diversity mediate the relationship between the television variables and anti-immigrant sentiments. Frequently watching television is positively related to fear of crime $(b=.034, p<.05)$, which in turn is positively related to anti-immigrant sentiments $(b=.319, \mathrm{p}<.001)$. In addition, frequently watching television is positively related to perceived ethnic diversity $(b=.970$, $\mathrm{p}<.001)$, which in turn is positively related to anti-immigrant sentiments $(b=.010, p<.001)$. Fear of crime and perceived ethnic diversity function as mediators as well between preference for public television and anti-immigrant sentiments. A preference for public television is negatively related to both fear of crime $(b=-.080, \mathrm{p}<.01)$ and perceived ethnic diversity $(b=-4.789, \mathrm{p}<.001)$. Moreover, there is a direct, negative relation between preference for public television and antiimmigrant sentiments $(b=-.529, \mathrm{p}<.001)$.

\section{- Figure 1-}

We can thus conclude that, while audience traits are important, neighborhood characteristics are only weakly correlated with perceived ethnic diversity, fear of crime and

\footnotetext{
${ }^{5}$ Model fit statistics show a good fit for the proposed model. $X^{2}(2)=1.146$, ns, Root Mean Square Error of Approximation $[$ RMSEA $]=0.000$, Comparative Fit Index $[\mathrm{CFI}]=1.000$. The Chi Square in the SEM model has a value of 1.14, and when the Chi Square is lower or equal to the degrees of freedom the RMSEA adopts a value of 0 and the CFI of 1. It is thus more informative to consider the value of the Chi Square in this regard and as this value is low and not significant, this suggests a good model fit. Formula RMSEA $=\sqrt{ }\left(\left(X^{\wedge} 2 / d f-1\right) /(N-1)\right)$.
} 
anti-immigrant sentiments. The relations between television and these attitudes, however, remain intact.

\section{Discussion}

This primary aim of this paper was to examine the role of television consumption in the formation of anti-immigrant sentiments. The initial expectation was that perceptions rather than real-life conditions matter when investigating determinants of anti-immigrant sentiments. Results largely confirmed this expectation. Frequently watching television is associated with higher fear of crime and perceived ethnic diversity, which is in turn associated with higher antiimmigrant sentiments. However, the type of television broadcaster greatly matters: preference for public stations, compared to commercial stations, has a direct negative association with antiimmigrant sentiments, lower fear of crime and perceived ethnic diversity. These correlations remain even while controlling for audience traits and neighborhood characteristics.

It turns out that the neighborhood characteristics that were examined, i.e. real ethnic diversity and crime levels, play a relatively minor role in explaining anti-immigrant sentiments, fear of crime and perceived ethnic diversity. Apparently real immigrants presence and actual crime figures in the neighborhood, have little bearing on these attitudes. This is in line with recent studies finding limited impact from immigration figures both at the national and municipal level on anti-immigrant attitudes (Hooghe \& de Vroome, 2015; Van Klingeren et al., 2014). Moreover, it corroborates evidence from studies on fear of crime suggesting that crime levels and fear of crime are not always empirically related. A possible explanation may be that it remains difficult for citizens to accurately estimate real-world developments. Still, some qualification is in order. The analysis does not allow for a conclusion that neighborhood characteristics do not matter at all, but simply shows that the specific variables in terms of ethnic diversity and crime levels that we considered did not explain much of the variation in anti-immigrant studies. Future studies might want to replicate these findings, expanding the 
number of neighborhood characteristics with other possible relevant indicators, such as poverty or unemployment levels.

Audience traits matter, but even controlling for these socio-demographic characteristics, the relationship between television and attitudes holds. We can therefore conclude that what mainly matters while evaluating immigrants are perceptions and that these perceptions are heavily shaped by patterns in television consumption. This highlights television's role as socialization agent in the immigration debate in Western European societies.

This study's main contribution is that it sheds light on the mechanisms through which television impacts anti-immigrant sentiments. Our results suggest that the influence of television exposure is not direct, but rather indirect as it affects anti-immigrant sentiments via other attitudes, i.e. perceived ethnic diversity and fear of crime. With regard to perceived ethnic diversity, we can speculate that television coverage of ethnic diversity primes the immigration topic, prompting worries about future immigration and immigration-related issues. This may lead individuals who frequently watch television to overestimate ethnic diversity levels in society, which in turn may provoke hostile attitudes toward immigrants. Moreover, a relevant question relates to how the correlation of fear of crime with anti-immigrant sentiments can be explained. Although our data do not allow us to be conclusive on this question, on a speculative note individuals may perceive an overrepresentation of immigrants in crime statistics, which may be stimulated by news content and elite rhetoric. There is evidence that in Western Europe, often cognitive associations are made between immigration and crime in the news (Caviedes, 2015; Lawlor, 2015) and that political rhetoric by right-wing anti-immigrant parties highlight criminal threats posed by immigrants (Rydgren, 2008). The tendency of television to construct linkages between immigration and crime has the potential to make fear of crime a powerful source of anti-immigrant sentiments. The prevalence of patterns of threat in television news coverage therefore warrants further investigation, as-even when real-life indicators suggest 
otherwise-majority group members tend to believe images constructed by television. What specific type of news content could be associated with these effects, however, still has to be determined. It is important to note, however, that the crime-related causal mechanism apparently is just as strong in Western European societies as in the US context, despite lower crime levels and a different ethnic composition of the population in Western Europe.

Watching television, however, can also be related to lower anti-immigrant sentiments, but this is dependent upon the type of broadcaster: a preference for public broadcasters is associated with lower anti-immigrant sentiments, perceived ethnic diversity and fear of crime levels, suggesting that public and commercial broadcasters may diverge in their framing of minorities and the immigration debate. This could be explained by both broadcasters' distinct goal attainment, which may elicit different journalistic and news production values, likely reflecting in actual news content. Whereas public broadcasters follow a public logic, aimed at fostering democratic values in society, commercial broadcasters are mainly guided by a marketlogic (Rogers et al., 2014). More specifically, crime and immigration may be covered in a more sensational way on commercial television than on public television. Moreover, we know that crime is a popular ingredient of commercial news, because the issue is widely recognized to attract a large audience, straightforward, and simplistic (Lowry et al., 2003). Past studies have indeed shown that crime coverage is more prevalent on Flemish commercial news (Walgrave \& De Swert, 2002). Future research efforts should therefore systematically content analyze immigration news coverage while differentiating between broadcasters, pinpointing whether differences in content can explain this attitudinal gap.

Notwithstanding its contributions, this study has several limitations. First, although the inclusion of real-life crime statistics presents an advantage, crime statistics inevitably underestimate real crime levels. Nevertheless, Belgian law enforcement has heavily invested in developing a uniform procedure for reporting and registering criminal acts. Second, our data is 
geographically limited to Flanders. Although at first sight, the integration of non-nationals seems more difficult in a small language region, compared to a major language region like the French region, analysis of the European Social Survey (2008 and 2010) shows that Dutch and French-language respondents do not hold significantly different attitudes toward immigrants. Moreover, the Belgian migration context and television market are not exceptional compared to other Western European countries either. Third, due to data limitations, we could not rely on more detailed data on media use to obtain content-specific measures as well. Future studies may therefore want to include more measures on specific types and content of media use. Finally, we rely on cross-sectional survey data, which does not permit us to make causal claims. Nevertheless, we consider it safe to conclude that future efforts to explain the relation between television and anti-immigrant sentiments should also pay attention to patterns of criminal threat. Although this relation has received systematic attention in US-based research, too often it is neglected in research on European societies. Despite lower crime levels in most Western European countries compared to the US, crime and fear of crime seem to be strongly related to anti-immigrant sentiments in these societies too, and our results suggest that television plays an important role in this relation.

\section{References}

Aarts, K., \& Semetko, H. A. (2003). The divided electorate: Media use and political involvement. Journal of Politics, 65(3), 759-784.

Alba, R., Rumbaut, R. G., \& Marotz, K. (2005). A distorted nation: Perceptions of racial/ethnic group sizes and attitudes toward immigrants and other minorities. Social Forces, 84(2), 901-919.

Bauder, H. (2008). Immigration debate in Canada: How newspapers reported, 1996-2004. Journal of International Migration and Integration, 9(3), 289-310.

Bircan, T., \& Hooghe, M. (2011). Immigration, diversity and crime: An analysis of Belgian national crime statistics, 2001-6. European Journal of Criminology, 8(3), 198-212.

Bohman, A., \& Hjerm, M. (2013). How the religious context affects the relationship between religiosity and attitudes towards immigration. Ethnic and Racial Studies, 37(6), 937-957. 
Boomgaarden, H. G., \& Vliegenthart, R. (2009). How news content influences antiimmigration attitudes: Germany, 1993-2005. European Journal of Political Research, 48(4), 516-542.

Burns, P., \& Gimpel, J. G. (2000). Economic insecurity, prejudicial stereotypes, and public opinion on immigration policy. Political Science Quarterly, 115(2), 201-225.

Ceobanu, A. M. (2011). Usual suspects? Public views about immigrants' impact on crime in European countries. International Journal of Comparative Sociology, 52(1-2), 114-131.

Chadee, D., \& Ditton, J. (2005). Fear of crime and the media: Assessing the lack of relationship. Crime, Media, Culture, 1(3), 322-332.

Charteris-Black, J. (2006). Britain as a container: Immigration metaphors in the 2005 election campaign. Discourse \& Society, 17(5), 563-581.

Chiricos, T., Hogan, M., \& Gertz, M. (1997). Racial composition of neighborhood and fear of crime. Criminology, 35(1), 107-132.

Chiricos, T., Padgett, K., \& Gertz, M. (2000). Fear, TV news, and the reality of crime. Criminology, 38(3), 755-786.

Citrin, J., Green, D. P., Muste, C., \& Wong, C. (1997). Public opinion toward immigration reform: The role of economic motivations. The Journal of Politics, 59(3), 858-881.

Dinas, E., \& van Spanje, J. (2011). Crime story: The role of crime and immigration in the anti-immigration vote. Electoral Studies, 30(4), 658-671.

Dunaway, J., Branton, R. P., Abrajano, M. A., \& Diego, S. (2010). Agenda setting, public opinion, and the issue of immigration reform. Social Science Quarterly, 91(2), 359-378.

Eschholz, S., Chiricos, T., \& Gertz, M. (2003). Television and fear of Crime: Program types, audience Traits, and the mediating effect of perceived neighborhood racial composition. Social Problems, 50(3), 395-415.

Esser, F., \& de Vreese, C. H. (2007). Comparing young voters' political engagement in the United States and Europe. American Behavioral Scientist, 50(9), 1195-1213.

European Audiovisual Observatory. (2014). A unique information source on the audiovisual sector in Europe. Retrieved from http://www.obs.coe.int/about

Fitzgerald, J., Curtis, A. K., \& Corliss, C. L. (2011). Anxious publics: Worries About crime and immigration. Comparative Political Studies, 45(4), 477-506.

Fryberg, S. A., Stephens, N. M., Covarrubias, R., Markus, H. R., Carter, E. D., Laiduc, G. A., \& Salido, A. J. (2012). How the media frames the immigration debate: The critical role of location and politics. Analyses of Social Issues and Public Policy, 12(1), 96-112.

Gerbner, G., Gross, L., Morgan, M., Signorielli, N., \& Shanahan, J. (2002). Living with Television: The Dynamics of the Cultivation Process. In J. Bryant \& D. Zillmann (Eds.), Media effects: Advances in Theory and Research (pp. 17-40). Mahwah, N J: Lawrence 
Erlbaum.

Gray, J., \& Lotz, A. D. (2011). Television Studies. Oxford: Polity.

Hainmueller, J., \& Hiscox, M. J. (2010). Attitudes toward highly skilled and low-skilled immigration: Evidence from a survey experiment. American Political Science Review, 104(1), 61-84.

Heath, L., \& Gilbert, K. (1996). Mass media and rear of crime. American Behavioral Scientist, 39(4), 379-386.

Holtz-Bacha, C., \& Norris, P. (2001). “To entertain, inform, and educate": Still the role of public television. Political Communication, 18(2), 123-140.

Hooghe, M. (2002). Watching television and civic engagement: Disentangling the effects of time, programs, and stations. Harvard International Journal of Press/Politics, 7(2), 84104.

Hooghe, M. (2012). I'm Happy, Hope You're Happy Too Examining the Different Dynamics of Individual Subjective Well-Being and View on Society. Journal of Happiness Studies, 13(1), 17-29.

Hooghe, M., \& de Vroome, T. (2015). The perception of ethnic diversity and anti-immigrant sentiments: A Multilevel analysis of local communities in Belgium. Ethnic and Racial Studies, 38(1), 38-56.

Hooghe, M., Vanhoutte, B., \& Bircan, T. (2009). Technical report for the social cohesion survey Flanders 2009 (SCIF 2009). Leuven: University of Leuven.

Ivarsflaten, E. (2005). Threatened by diversity: Why restrictive asylum and immigration policies appeal to western Europeans. Journal of Elections, Public Opinion \& Parties, 15(1), 21-45.

Iyengar, S., \& Gilliam, F. D. (2000). Prime suspects: The influence of local television news on the viewing public. American Journal of Political Science, 44(3), 560-573.

Iyengar, S., \& Kinder, D. R. (1987). News that matters: Television and American opinion. Chicago, IL: University of Chicago Press.

Kline, R. B. (Ed.). (2011). Principles and Practice of Structural Equation Modeling. New York: The Guilford Press.

Kriesi, H., Grande, E., Dolezal, M., Helbling, M., Hutter, S., \& Wüest, B. (2012). Political Conflict in Western Europe. Cambridge: Cambridge University Press.

Kunovich, R. M. (2004). Social structural position and prejudice: an exploration of crossnational differences in regression slopes. Social Science Research, 33(1), 20-44.

Kunovich, R. M. (2013). Labor market competition and anti-immigrant sentiment: Occupations as contexts. International Migration Review, 47(3), 643-685. 
Lancee, B., \& Pardos-Prado, S. (2013). Group conflict theory in a longitudinal perspective: Analyzing the dynamic side of ethnic competition. International Migration Review, 47(1), 106-131.

Lawlor, A. (2015). Local and national accounts of immigration framing in a cross-national perspective. Journal of Ethnic and Migration Studies, (August), 1-24.

LeVine, R. A., \& Campbell, D. T. (1972). Ethnocentrism: Theories of conflict, ethnic attitudes, and group behavior. New York: Wiley.

Lowry, D. T., Nio, T. C. J., \& Leitner, D. W. (2003). Setting the public fear agenda: A longitudinal analysis of network TV crime reporting, public perceptions of crime, and FBI crime statistics. Journal of Communication, 53(1), 61-73.

Lubbers, M., Scheepers, P., \& Wester, F. (1998). Ethnic minorities in Dutch newspapers 1990-5. Patterns of criminalization and problematization. Gazette, 60(5), 415-431.

Morelli, A. (2004). Histoire des étrangers et de l'immigration en Belgique de la préhistoire à nos jours. [A History of foreigners and immigration in Belgium from prehistoy until now]. Charleroi: Couleur Livres.

Pettigrew, T. F., \& Tropp, L. R. (2008). How does intergroup contact reduce prejudice? Metaanalytic tests of three mediators. European Journal of Social Psychology, 38(1), 922934.

Pickett, J. T., Chiricos, T., Golden, K. M., \& Gertz, M. (2012). Reconsidering the relationship between perceived neighborhood racial composition and whites' perceptions of victimization risk: Do racial stereotypes matter? Criminology, 50(1), 145-186.

Prior, M. (2009). Improving media effects research through better measurement of news exposure. Journal of Politics, 71(3), 893-908.

Quillian, L. (1995). Prejudice as a response to perceived group threat : Population composition and anti-immigrant and racial prejudice in Europe. American Sociological Review, 60(4), 586-611.

Quillian, L., \& Pager, D. (2001). Neighborhood crime black neighbors, higher crime? The role of racial stereotypes in evaluations of neighborhood crime. American Journal of Sociology, 107(3), 717-767.

Raijman, R., \& Semyonov, M. (2004). Perceived threat and exclusionary attitudes towards foreign workers in Israel. Ethnic and Racial Studies, 27(5), 780-799.

Riek, B. M., Mania, E. W., \& Gaertner, S. L. (2006). Intergroup threat and outgroup attitudes: A meta-analytic review. Personality and Social Psychology Review, 10(4), 336-353.

Rogers, J., O’Boyle, N., Preston, P., \& Fehr, F. (2014). The significance of small differences: Cultural diversity and broadcasting in Ireland. European Journal of Communication, 29(4), 399-415. 
Rustenbach, E. (2010). Sources of negative attitudes toward immigrants in Europe: A multilevel analysis. International Migration Review, 44(1), 53-77.

Rydgren, J. (2008). Immigration Sceptics, Xenophobes or Racists? Radical Right-Wing Voting in Six West European Countries. European Journal of Political Research, 47(6), 737-765.

Schemer, C. (2012). The influence of news media on stereotypic attitudes toward immigrants in a political campaign. Journal of Communication, 62(5), 739-757.

Schlueter, E., \& Davidov, E. (2013). Contextual sources of perceived group threat: Negative immigration-related news teports, immigrant group size and their interaction, Spain 1996-2007. European Sociological Review, 29(2), 179-191.

Schlueter, E., \& Scheepers, P. (2010). The relationship between outgroup size and antioutgroup attitudes: A theoretical synthesis and empirical test of group threat- and intergroup contact theory. Social Science Research, 39, 285-295.

Schmitt-Beck, R., \& Wolsing, A. (2010). European TV environments and citizens' social trust: Evidence from multilevel analyses. Communications, 35(4), 461-483.

Schneider, S. L. (2008). Anti-immigrant attitudes in Europe: Outgroup size and perceived ethnic threat. European Sociological Review, 24(1), 53-67.

Semyonov, M., Raijman, R., \& Gorodzeisky, A. (2006). The rise of anti-foreigner sentiment in European societies, 1988-2000. American Sociological Review, 71(3), 426-449.

Sides, J., \& Citrin, J. (2007). European opinion about immigration: The role of identities, interests and information. British Journal of Political Science, 37(3), 477-504.

Strabac, Z., \& Listhaug, O. (2008). Anti-Muslim prejudice in Europe: A multilevel analysis of survey data from 30 countries. Social Science Research, 37(1), 268-286.

Stupi, E. K., Chiricos, T., \& Gertz, M. (2014). Perceived criminal threat from undocumented immigrants: Antecedents and consequences for policy preferences. Justice Quarterly, (May), 1-28.

Valentova, M., \& Alieva, A. (2014). Gender differences in the perception of immigrationrelated threats. International Journal of Intercultural Relations, 39(1), 175-182.

Van Klingeren, M., Boomgaarden, H. G., Vliegenthart, R., \& De Vreese, C. H. (2014). Real world is not enough: The media as an additional source of negative attitudes toward immigration, comparing Denmark and the Netherlands. European Sociological Review, $31(3), 268-283$.

Visser, M., Scholte, M., \& Scheepers, P. (2013). Fear of crime and feelings of unsafety in European countries: Macro and micro explanations in cross-national perspective. Sociological Quarterly, 54(2), 278-301.

Walgrave, S., \& De Swert, K. (2002). Does news content matter? The contribution of the 
news media in the making of the issues of the Vlaams Blok. Ethical Perspectives, 9(4), 249-274.

Weitzer, R., \& Kubrin, C. E. (2004). Breaking news: How local TV news and real-world conditions affect fear of crime. Justice Quarterly, 21(3), 497-520. 
Figure 1. Direct and indirect relations between television consumption and anti-immigrant sentiments, controlling for audience and neighborhood characteristics

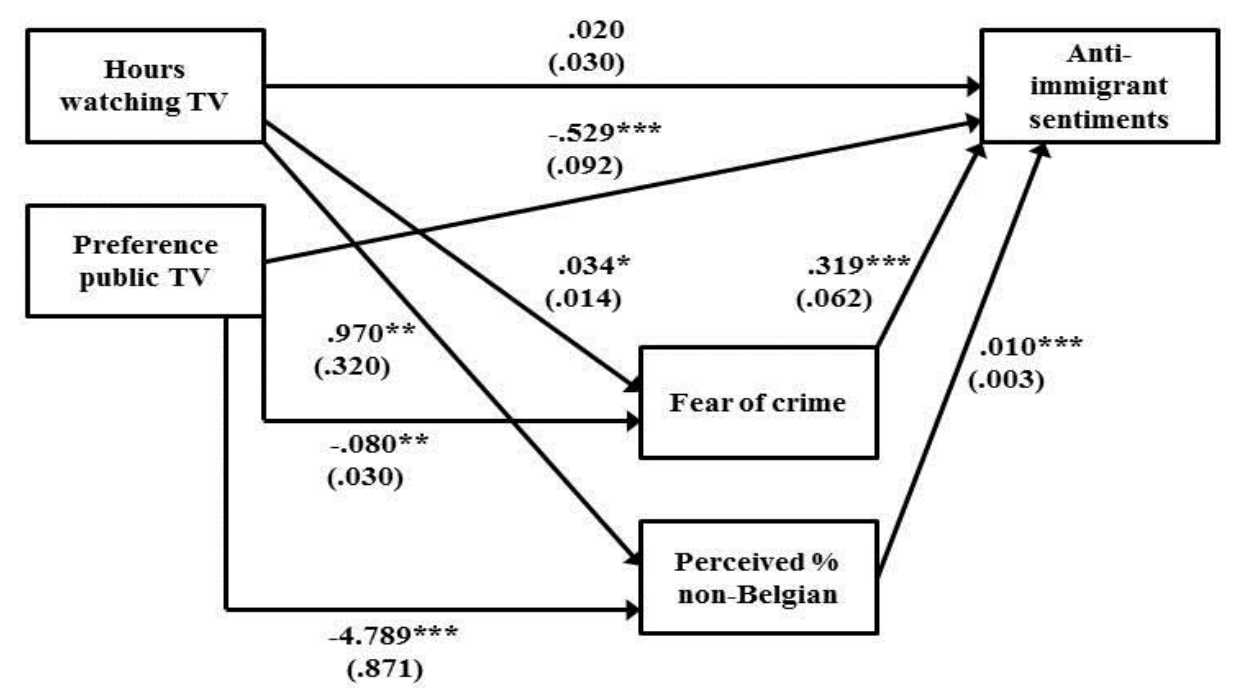

Source: SCIF 2009. N=1657. *** $\mathrm{p}<.001, * * \mathrm{p}<.01, * \mathrm{p}<.05$ (two-tailed). Notes: Reported are the unstandardized relations (standard errors in parentheses), results of a SEM analysis in MPLUS. Estimation controls for audience traits and neighborhood characteristics. 
Table 1. Audience traits and neighborhood characteristics for the model of television consumption and anti-immigrant sentiments

\begin{tabular}{|c|c|c|c|c|c|}
\hline Path & & & $\mathbf{B}$ & se & $\mathbf{p}$ \\
\hline \multicolumn{6}{|l|}{ Individual level } \\
\hline Anti-immigrant sentiments & $\leftarrow$ & Female & -.244 & .093 & $* *$ \\
\hline Anti-immigrant sentiments & $\leftarrow$ & Age & .010 & .003 & $* * *$ \\
\hline Anti-immigrant sentiments & $\leftarrow$ & Education & -.265 & .046 & $* * *$ \\
\hline Anti-immigrant sentiments & $\leftarrow$ & Long-term unemployment & -.007 & .108 & \\
\hline Anti-immigrant sentiments & $\leftarrow$ & Income satisfaction & -.066 & .030 & * \\
\hline Anti-immigrant sentiments & $\leftarrow$ & Life satisfaction & -.123 & .026 & $* * *$ \\
\hline Anti-immigrant sentiments & $\leftarrow$ & Intergroup friendship & -.678 & .103 & $* * *$ \\
\hline Anti-immigrant sentiments & $\leftarrow$ & Religiosity & -.273 & .101 & $* *$ \\
\hline Anti-immigrant sentiments & $\leftarrow$ & Victimization & -.076 & .114 & \\
\hline Anti-immigrant sentiments & $\leftarrow$ & Left-right self-placement & .122 & .028 & $* * *$ \\
\hline Anti-immigrant sentiments & $\leftarrow$ & Single household & -.192 & .154 & \\
\hline Fear of crime & $\leftarrow$ & Female & .347 & .038 & $* * *$ \\
\hline Fear of crime & $\leftarrow$ & Age & .004 & .001 & $* *$ \\
\hline Fear of crime & $\leftarrow$ & Education & -.051 & .013 & $* * *$ \\
\hline Fear of crime & $\leftarrow$ & Long-term unemployment & -.043 & .051 & \\
\hline Fear of crime & $\leftarrow$ & Income satisfaction & -.012 & .015 & \\
\hline Fear of crime & $\leftarrow$ & Life satisfaction & -.019 & .012 & \\
\hline Fear of crime & $\leftarrow$ & Intergroup friendship & -.083 & .035 & $*$ \\
\hline Fear of crime & $\leftarrow$ & Religiosity & .119 & .030 & $* * *$ \\
\hline Fear of crime & $\leftarrow$ & Victimization & .136 & .043 & ** \\
\hline Fear of crime & $\leftarrow$ & Left-right self-placement & .007 & .009 & \\
\hline Fear of crime & $\leftarrow$ & Single household & .105 & .061 & \\
\hline Perceived $\%$ non-Belgian & $\leftarrow$ & Female & 8.464 & .712 & $* * *$ \\
\hline Perceived $\%$ non-Belgian & $\leftarrow$ & Age & -.127 & .024 & $* * *$ \\
\hline Perceived $\%$ non-Belgian & $\leftarrow$ & Education & -2.211 & .404 & $* * *$ \\
\hline Perceived $\%$ non-Belgian & $\leftarrow$ & Long-term unemployment & 1.752 & .992 & r \\
\hline Perceived $\%$ non-Belgian & $\leftarrow$ & Income satisfaction & -.173 & .377 & \\
\hline Perceived $\%$ non-Belgian & $\leftarrow$ & Life satisfaction & .041 & .251 & \\
\hline Perceived $\%$ non-Belgian & $\leftarrow$ & Intergroup friendship & -.880 & .838 & \\
\hline Perceived $\%$ non-Belgian & $\leftarrow$ & Religiosity & -.182 & .768 & \\
\hline Perceived $\%$ non-Belgian & $\leftarrow$ & Victimization & .459 & 1.317 & \\
\hline Perceived $\%$ non-Belgian & $\leftarrow$ & Left-right self-placement & .488 & .167 & $* *$ \\
\hline Perceived $\%$ non-Belgian & $\leftarrow$ & Single household & 2.672 & 1.329 & $*$ \\
\hline \multicolumn{6}{|l|}{ Neighborhood level } \\
\hline Anti-immigrant sentiments & $\leftarrow$ & $\%$ Turks & -.004 & .123 & \\
\hline Anti-immigrant sentiments & $\leftarrow$ & $\%$ Moroccans & .291 & .104 & $* *$ \\
\hline Anti-immigrant sentiments & $\leftarrow$ & $\%$ Eastern Europeans & -.010 & .123 & \\
\hline Anti-immigrant sentiments & $\leftarrow$ & $\%$ Inflow foreigners & -.074 & .175 & \\
\hline Anti-immigrant sentiments & $\leftarrow$ & Property crime rate & -.005 & .012 & \\
\hline Anti-immigrant sentiments & $\leftarrow$ & Violent crime rate & -.018 & .022 & \\
\hline Fear of crime & $\leftarrow$ & $\%$ Turks & .097 & .094 & \\
\hline Fear of crime & $\leftarrow$ & $\%$ Moroccans & .212 & .122 & \\
\hline Fear of crime & $\leftarrow$ & $\%$ Eastern Europeans & -.065 & .077 & \\
\hline Fear of crime & $\leftarrow$ & $\%$ Inflow foreigners & .074 & .121 & \\
\hline Fear of crime & $\leftarrow$ & Property crime rate & .003 & .005 & \\
\hline Fear of crime & $\leftarrow$ & Violent crime rate & .008 & .009 & \\
\hline Perceived $\%$ non-Belgian & $\leftarrow$ & $\%$ Turks & 2.802 & 1.140 & * \\
\hline Perceived $\%$ non-Belgian & $\leftarrow$ & $\%$ Moroccans & 3.336 & .431 & $* * *$ \\
\hline Perceived $\%$ non-Belgian & $\leftarrow$ & $\%$ Eastern Europeans & -1.706 & .874 & \\
\hline Perceived $\%$ non-Belgian & $\leftarrow$ & $\%$ Inflow foreigners & .223 & 1.240 & \\
\hline
\end{tabular}

Source: SCIF 2009. N=1657. *** $\mathrm{p}<.001, * * \mathrm{p}<.01, * \mathrm{p}<.05$, (two-tailed). Notes: Entries are the result of a SEM analysis in MPLUS. Reported are the unstandardized coefficients (b), standard errors (se) and significance values (p). 
Table 2. Specific relationships between television consumption and anti-immigrant sentiments

\begin{tabular}{|c|c|c|c|c|c|c|}
\hline & & & & b & se & $\mathbf{p}$ \\
\hline \multicolumn{7}{|c|}{ Effects of time spent watching $T V$} \\
\hline Anti-immigrant sentiments & $\leftarrow$ & Hours watching TV & (Total) & .041 & .032 & \\
\hline Anti-immigrant sentiments & $\leftarrow$ & Hours watching TV & (Direct) & .020 & .030 & \\
\hline Anti-immigrant sentiments & $\leftarrow$ & Hours watching TV & (Indirect) & .021 & .006 & $* *$ \\
\hline Anti-immigrant sentiments & $\leftarrow$ & Fear of crime & $\leftarrow$ Hours watching TV & .011 & .006 & \\
\hline Anti-immigrant sentiments & $\leftarrow$ & $\begin{array}{l}\text { Perceived \% non- } \\
\text { Belgian }\end{array}$ & $\leftarrow$ Hours watching TV & .010 & .004 & \\
\hline \multicolumn{7}{|c|}{ Effects of preference for public TV channels } \\
\hline Anti-immigrant sentiments & $\leftarrow$ & Preference public TV & (Total) & -.603 & .092 & $* * *$ \\
\hline Anti-immigrant sentiments & $\leftarrow$ & Preference public TV & (Direct) & -.529 & .092 & $* * *$ \\
\hline Anti-immigrant sentiments & $\leftarrow$ & Preference public TV & (Indirect) & -.073 & .017 & $* * *$ \\
\hline Anti-immigrant sentiments & $\leftarrow$ & Fear of crime & $\leftarrow$ Preference public TV & -.025 & .011 & $*$ \\
\hline Anti-immigrant sentiments & $\leftarrow$ & $\begin{array}{l}\text { Perceived \% non- } \\
\text { Belgian }\end{array}$ & $\leftarrow$ Preference public TV & -.048 & .017 & $* *$ \\
\hline
\end{tabular}

Source: SCIF 2009. N=1657. *** $\mathrm{p}<.001, * * \mathrm{p}<.01, * \mathrm{p}<.05$, (two-tailed). Notes: Entries are the result of a SEM analysis in MPLUS. Reported are the unstandardized coefficients (b), standard errors (se) and significance values (p). Estimation controls for audience traits and neighborhood characteristics. 


\section{Appendix: Table A.1.}

Descriptive statistics of variables included in the analysis

\begin{tabular}{|c|c|c|c|c|}
\hline & Min. & Max. & Mean & SD \\
\hline \multicolumn{5}{|l|}{ Dependent variable } \\
\hline Anti-immigrant sentiments & 0 & 10 & 4.919 & 1.830 \\
\hline \multicolumn{5}{|l|}{ Mediators } \\
\hline Fear of crime & 0 & 4 & .584 & .721 \\
\hline Perceived $\%$ non-Belgian & 1 & 99 & 27.184 & 16.736 \\
\hline \multicolumn{5}{|l|}{ Independent variables } \\
\hline Hours watching TV & 0 & 11.5 & 2.401 & 1.562 \\
\hline Preference for public TV & 0 & 1 & .546 & \\
\hline \multicolumn{5}{|l|}{ Audience traits } \\
\hline Gender $=$ Female & 0 & 1 & .506 & \\
\hline Age & 18 & 85 & 48.418 & 17.846 \\
\hline Education level & 0 & 5 & 3.084 & 1.126 \\
\hline Long-term unemployment & 0 & 1 & .147 & \\
\hline Income satisfaction & 0 & 5 & 3.449 & 1.078 \\
\hline Life satisfaction & 0 & 10 & 7.946 & 1.525 \\
\hline Intergroup friendship & 0 & 1 & .345 & \\
\hline Religiosity & 0 & 1 & .494 & \\
\hline Victimization past five years & 0 & 1 & .161 & \\
\hline Left-right self-placement & 0 & 10 & 5.366 & 2.094 \\
\hline Single household & 0 & 1 & .123 & \\
\hline \multicolumn{5}{|l|}{ Neighborhood characteristics } \\
\hline$\%$ Turks & 0 & 2.02 & .378 & .578 \\
\hline$\%$ Moroccans & 0 & 2.53 & .355 & .664 \\
\hline$\%$ Eastern Europeans & .13 & 3.00 & .914 & .802 \\
\hline$\%$ Inflow foreigners & 0 & 1.80 & .389 & .316 \\
\hline Property crime rate/1000 inhabitants & 9.93 & 71.23 & 31.516 & 17.202 \\
\hline Violent crime rate/1000 inhabitants & 3.64 & 29.72 & 14.095 & 6.669 \\
\hline
\end{tabular}

Source: SCIF 2009, National Institute for Statistics and Belgian Federal Police. N=1657. 


\section{Appendix: Table A.2}

Covariances, residual variances and intercepts for the final model

\begin{tabular}{|c|c|c|c|c|}
\hline & & $\mathbf{b}$ & se & $\mathbf{p}$ \\
\hline \multicolumn{5}{|l|}{ Individual level } \\
\hline \multicolumn{5}{|l|}{ Covariances } \\
\hline Fear of crime & W. Perceived $\%$ non-Belgian & .334 & .234 & \\
\hline \multicolumn{5}{|l|}{ Residual variances } \\
\hline Anti-immigrant sentiments & & 2.450 & .096 & $* * *$ \\
\hline Fear of crime & & .406 & .037 & $* * *$ \\
\hline Perceived $\%$ non-Belgian & & 227.405 & 10.711 & $* * *$ \\
\hline \multicolumn{5}{|l|}{ Neighborhood level } \\
\hline \multicolumn{5}{|l|}{$\overline{\text { Covariances }}$} \\
\hline Fear of crime & W. Perceived $\%$ non-Belgian & .048 & .064 & \\
\hline Anti-immigrant sentiments & W. Perceived $\%$ non-Belgian & -.194 & .180 & \\
\hline Anti-immigrant sentiments & W. Fear of crime & .022 & .011 & $*$ \\
\hline \multicolumn{5}{|l|}{ Residual variances } \\
\hline Anti-immigrant sentiments & & .047 & .030 & \\
\hline Fear of crime & & .022 & .012 & \\
\hline Perceived $\%$ non-Belgian & & 4.582 & 2.691 & \\
\hline \multicolumn{5}{|l|}{ Intercepts } \\
\hline Anti-immigrant sentiments & & 6.925 & .368 & $* * *$ \\
\hline Fear of crime & & .159 & .132 & \\
\hline Perceived $\%$ non-Belgian & & 32.817 & 3.355 & $* * *$ \\
\hline
\end{tabular}

Source: SCIF 2009. N=1657. *** $\mathrm{p}<.001, * * \mathrm{p}<.01, * \mathrm{p}<.05$, (two-tailed). Notes: Entries are the result of a SEM analysis in MPLUS. Reported are the unstandardized estimates (b), standard errors (se) and significance values (p). 
Appendix: Table A.3

R-squares final model

Estimate

Individual level

Anti-immigrant sentiments

.246

Fear of crime

.141

Perceived \% non-Belgian

.163

Neighborhood level

Anti-immigrant sentiments

Fear of crime

.598

Perceived \% non-Belgian

.527

Source: Source: SCIF 2009. N=1657. 